\title{
ALLEVIATING GENDER INEQUALITIES IN PUBLIC COMMUNITY LEARNING CENTRES IN THE EASTERN CAPE
}

\author{
X. Tawana* \\ ABET and Youth development \\ https://orcid.org/0000-0003-2274-0264 \\ P. Higgs* \\ Philosophy of Education \\ https://orcid.org/0000-0003-2563-4336
}

*University of South Africa

Pretoria, South Africa

\section{ABSTRACT}

This article examines the problem of gender inequalities in Public Community Learning Centres in the Eastern Cape. It does so, to propose an alternative plan in which these centres might possibly help female adult learners reduce gender inequalities in everyday life in their communities. In short, the problem is: Public Community Learning Centres are mandated to advance equity and redress, and it is apparent that they do not in fact help or encourage communities to alleviate gender inequalities in the Eastern Cape. Determining why female adult learners do not take part in the in the economy of their communities will assist policy makers and these Public Community Learning Centres to come up with new initiatives that will address the needs and interests of female adult learners. This article was grounded on a Postcolonial Indigenous Paradigm which advocates for researcher accountability to the web of relations in which the research is conducted. Mixed Focus Groups discussions were conducted for adult learner participants to develop new understandings regarding gender relations as they interacted with each other around the theme of gender inequalities in their communities. Two Public Community Learning Centres located in a suburban and an inner city of the Eastern Cape were selected to conduct the research. The results of this study indicated that gender inequalities are present in closed doors and publicized bubbles in the Eastern Cape. In the light of this, and as a result of the research undertaken, recommendations are made to address the problem of gender inequalities in Community Learning Centres in the Eastern Cape.

Keywords: Public Community Learning Centres, gender inequalities, equitable, socio-economic advancement, Postcolonial Indigenous Paradigm, African feminist thinking

\section{INTRODUCTION}

In the contemporary world education has been seen by many as the tool for development and eliminating ignorance among people. As a result, many adults who were not able to acquire 
basic education when they were young because of varied reasons are afforded with basic training aligned with constitutional services and global convections, namely, Education for All (United Nations 2006, 06). However, in most developing countries, especially Africa South of Sahara, socio-cultural practices, economic and political conditions continue to deny thousands of women to acquire basic training.

There are some tribes where husbands assume that once lobola (bride price) is paid off, they have purchased their wives and could use them as they want. From an early age, children learn that their characteristics are contained in gender roles stereotypes. These stereotypes fall under the so called feminine or masculine stereotypes. Once individuals have acquired these roles, they develop into a pattern and teach males and females to behave in a certain way. It can therefore be argued that the socializing agents play a major role in perpetuating the gender inequalities in our communities. This procedure is guided by culture, including the individual's historical and ethnic background and geographical location (Lindsey 2005, 51).

The socialization process is thus transmitted to individuals through several socializing agents or regimes present in each community such as, family, religion and traditional institutions. These societal institutions work together and directly or indirectly help to reinforce gender imbalances in a society. In most African cultures women are stereotyped as emotional, talkative, weak, homemakers, sympathetic, inferior in terms of intelligence and so on. Men are not supposed to show emotions, they are supposed to be strong, aggressive, ambitious, possess leadership skills, and in general, be superior to their female counterparts (Mazile 1998; Lindsey 2005). Such a view weaken femininity as they are portrayed as lesser than their male counterparts.

In this article, the problem of gender inequality is used to suggest that females, more especially those residing in isolation usually endure the gist of gender inequalities in their communities. Gender inequalities are clear from other manifestations of socio-demographic differences. They occur inside and outside the home Klassen and Lamanna (2009, 93) asserts that gender inequalities have a negative effect on development goals as they prevent women from participating in socio-economic development of communities.

In responding to this problem, the present article explores the key causes that maintain gender inequalities and how these occurrences effect the socio-economic development of females in their communities. Furthermore, this article attempts to suggest different approaches that can be employed in Public Community Learning Centres to help young women alleviate the distinctions between the males and females which give rise to gender inequalities.

In implementing the research design employed in this investigation, the Focus Group Guide included pre-planned arranged questions, though the men and women who participated 
in the study were advised that the interview would not hamper their arguments or analysis. We kept the interview as an informal conversation, and records were kept for data analysis. The questions asked were paraphrased as follows:

1. What do gender inequalities signify to you as males and females?

2. Do you think the males and females are afforded equal treatment in your community?

3. What are the explanations for these gender inequalities?

4. How do gender inequalities impact on the lives of women in your community?

5. In your judgement or point of view, can you suggest various ways in which Public Community Learning Centres could do to help male and females to alleviate gender inequalities.

In what follows we indicate what research design was used in embarking on the research undertaken in addressing the problem under investigation, namely, gender inequalities in Public Community Learning Centres in the Eastern Cape and, then go onto discuss the findings of the research undertaken in relation to the recommendations proposed when it comes to alleviating gender inequalities and the role that Public Communty Learning Centres in the Eastern Cape can play in this regard.

\section{RESEARCH DESIGN}

The research design which provided the research framework for investigating the research problem revolved around the question as to what the key factors are (as experienced) that sustain differences between men and women in communities in the Eastern Cape (for a detailed discussion of the research design see, Tawana, 2019, 79-85). These initial research design, which begun in 2016, later became what Creswell $(2003 ; 2013)$ calls an emergent design and what Poth (2018) calls an evolving design. It was initially set up to start with several individual interviews with female adult learners in selected communities of adult learning in the Eastern Cape. As a starting point and in order to gain some idea of how, if at all, gender mainstreaming was included in the curriculum of Public Community Learning Centres, mixed Focus Group discussions were conducted with men and women in each of the Public Community Learning Centres selected. No provision was initially made for the setting up of homogenous Face Group discussions with women only, as the idea was to organize cross-gender discussion. It was hoped that a stimulating and informative discussion would arise as men and women participants interacted with one another in the Face Group discussions and, in so doing highlighting different perspectives, but also the potential for learning from each other. The initial plan research design 
did not include two sets of Focus Group discussions (on different occasions with each of the selected educators in the selected Public Community Learning Centres) and two sets of (four) Face Group discussions with the student participants from mixed and homogenous groups. The need for this only arose as the study proceeded. While this was the final overall research design adopted, for the purpose of this article we concentrate only on the discussions in the mixed Face Group discussions in both the first (2016) and second (2018) sessions.

\section{Research paradigm}

The research design was grounded on a Postcolonial Indigenous Paradigm which advocates for researcher accountability to the web of relations in which the research is set. Chilisa (2012) points out that this implies that not only the researcher benefits by "gaining information", but the research participants also feel that the research has been worthwhile. The tenor of an indigenous research paradigm is that, in those countries of Africa that were colonized by the Europeans human beings or individuals are seen within the context of varied relationships and relatedness (Bantu 2013, 1; Chilisa 2012, 58). In such research, there is no attempt to "take distance" from the researched to strive for some supposed objectivity in the research process. Rather, there is an attempt to establish connectedness (intersubjectivity) with participants and to nurture connectivity all round (in the research space). Chilisa, Major and Khudu-Peterson (2017, 328). add that this also implies that the researcher feels a "belongingness" to the researched community without considering that's/he has thereby compromised the professional "researcher" role.

\section{Focus group discussions as data generating process}

Focus groups are often seen to derive data from multiple individuals simultaneously to gain some understanding of how people talk together around the topic of focus. Keeping with Romm's (2015) account of how Focus Group discussions can be facilitated in terms of an indigenous epistemological view of knowing as relational, the Focus Group sessions were set up as an opportunity for participants to develop deeper reflections on the topic under discussion as they participated together in the discussions. Data gathering was done in two phases (2016 and 2018). The Focus Group sessions were all about 1 hour and 20-30 minutes in length. As it happened the researcher (born in the Eastern Cape) had a working knowledge of IsiXhosa (the home language of the participants) and was conversant with oral use of the language, but not fully adept at writing it. We mostly used the home language of the participants, with some English being interjected by us and by the participants at certain points. The moderator (IsiXhosa speaking) also took notes during the sessions. This meant that when the facilitator 
and moderator compared transcripts and notes, a detailed understanding of the discussions could be developed. After the first set of mixed Focus Group discussions and further to them being transcribed and the notes of the moderator incorporated, a "member checking process" (Lincoln and Guba 1985; Anney 2014) was undertaken with participants. To this end, the researcher held a meeting with each group of participants to pinpoint issues which had arisen as important during the discussions and how the issues could be categorized. This meeting also helped to set the tone for the next mixed Focus Group discussions.

\section{Data collection and selection of participants}

A memo was written down to the managers of Public Community Learning Centres requesting for a permission to collect data. The managers of Public Community Learning Centres agreed that the Focus Group discussions could be conducted in the selected communities in the Eastern Cape district (see, Tawana 2019, 105). We assumed that the voices of the participants in these Public Community Learning Centres would be relevant to the problem under investigation. There were 35 adult learners in the selected centres (combined), of which only 24 participated voluntarily in the Focus Group discussions, with nineteen (19) being females and five (5) being males. (Tawana 2019, 106)

\section{Ethical considerations during data collection}

We requested for permission to record the conversations and guaranteed that participants would remain anonymous in the researcher's reporting. However, added to all of this, we adopted what (Chilisa 2009; Kovach 2009) refer to as an Indigenous Research Ethic whose intention is to serve the participants (and by implication their communities) by inviting discussion on questions regarded as being of concern not only to the researcher but also to the participants including the men and the women) The participants participated in the Focus Group discussions with some fervor, and nearly all agreed to take part in the second set of mixed sessions (as well as the other sessions). This points to a persistent level of interest in the discussions, indicating that the participants felt that they were deriving some benefit via their participation, as hoped for within an Indigenous Research Paradigm.

\section{RESPONSES OF THE PARTICIPANTS IN THE FIRST SET OF MIXED FOCUS GROUP DISCUSSIONSIN 2016}

In discussing the responses in the first set of mixed Focus Group discussions, we paraphrase and translate into English the responses from the male and female participants to the questions posed in the Focus Group Guide. In examining the transcripts and field notes (2016) it was 
noted that in the rural and urban Public Community Learning Centres certain themes were recurring in the participants responses. In checking on these recurring themes participants (via a meeting in each case) were asked whether they too felt that the themes identified resonated with the gist of the Focus Group discussions. At times, the participants themselves mentioned themes that they thought should be highlighted (such as, for example, the low status of women and lack of confidence), while at other times we suggested themes using non-jargonized language that would be understood by the participants and in so doing the participants also contributed to the naming of the themes. For the purposes of this article, we have summarized the collated themes, which all relate to key factors that were seen to perpetuate gender inequalities in Public Community Learning Centres in the Eastern Cape. Under each theme, we have identified different expressions of the theme, while pointing to some of the diverse "takes" that men and women had in relation to the theme. We have, therefore, specified whether the speaker in question is male or female, so that readers can get a sense of the differences, which at times showed that women and men were offering differing perspectives and also disagreeing, but there were also areas where agreements were being developed.

\section{Socialization}

One theme preferred by mainly the female participants as a factor leading to gender inequalities was the socialization process (which some called "programming process although some used the term socialized"). They expressed this variously as follows:

"As women when we were young, our guardians made sure we are guided against bad circumstances. We played in safe environments near our homes, and we were not allowed to explore the world." (Female participant).

We further asked if they think there are the ones who make the situations worse regarding differences in privileges participants noted that:

"We never question this instance because we feel is a norm that women should be treated like that." (Female participant).

"We are raised up to believe that men are better than us and can explore the outside world." (Female participant).

\section{Power dynamics}

One other motivation put forward regarding the differences awarded between men and women was that men like to control or dominate them. The women and men all in different ways expressed that woman are expected (and often expect themselves) to be led, and that women need to consult their husbands even in deciding whether to come to the Public Community 
Learning Centre. Below are their expressed words as paraphrased:

"In our communities, women are often discouraged to be leaders. If they do, they stand a chance of being dominated or discriminated and their platform may also not be visible." (Female participant).

"One participant pointed out that she had to request for approval from the husband before enrolling to the Centre so that she can prevent issues of domestic violence." (Female participant).

"In focus groups also, one man lamented that, men and women have different strengths and as such cannot be able to do jobs that are done by men." (Male participant).

Another male adult learner expressed that he was afraid that educated women may not respect their spouses and his views were paraphrased as follows:

"I don't wish for my wife to attend community education because women once educated, they begin to undermine their spouses." (Male participant).

"I forced my wife to spell out why she should get educated because she should look after our children." (Male participant).

As reflected in the various responses above, such cultural responses have also been recorded in many other cultural contexts by Western and African feminists alike. For example, Lindsey commenting on the power relations which she sees as persistent across the globe, asserts that, the roles, and attitudes that our communities stipulate as suitable for men and women results in issues of male domination in both the public and private spheres (Lindsey 2005, 53). These considerations have been argued to apply in various African contexts, as explained in the work of authors such as Ngulube (2018); Okoji and Ladeji (2014). Nevertheless, other authors who prefer to recognise the specificities of social contexts and the complexity of gendered relations - contend that African culture with its focus on relationality has the potential to offer different visions of the interdependence of men and women such that we need to theorise an African feminist vision to take this into account (e.g., Amaefula 2021; Adyanga 2019; Buswell and Corcoran-Nantes 2018; Matshidze 2013; Oyewumi 2002).

\section{Position of women}

Another factor leading to gender inequalities in this district was that females are awarded lesser status than men culturally. The reasons were provided by most of the females in Focus Group discussions.

"Our culture award status to our brothers when they come from initiations and these creates a problem because as their sisters, we are expected to respect them." (Female participant). 


\section{The influence of gender inequalities}

Regarding the influence of gender inequalities in Public Community Learning Centres, factors that influence gender inequalities were put forward and paraphrased as follows:

"Women will have lower status in their communities." (Female participant).

"Similarly, women would not be able to make decisions affecting their lives in the households." (Male participant).

"Some of the females' participants referred especially to the low employment status of women by suggesting that they will typically be housewives and domestic workers." (Female participants).

"The females will feel reluctant to take part in the economy of their communities." (Female participant).

"Women will start depending on men for survival and as a result endure instances of domestic violence." (Female participant).

\section{Fear and self-regard}

Another view raised by the female participants to explain the effects of imbalances when it comes to awarding privileges to males and females was that women would develop fear and feel hesitant to challenge men in job opportunities because of lack of self-regard. The sentiments put forward were paraphrased in this way:

"Women will fear to compete or apply for jobs because they will lack self-regard." (Female participant).

"Women will begin to believe that they cannot do anything for the betterment of their lives and as a result will not be motivated to try new things." (Female participant).

\section{Dependency in female-male relationships}

Concerning the question of dependency in female-male relationships, some of the learners (male and female) raised this issue by noting that in terms of the allocation of resources women in their communities would not be able to challenge men in job opportunities. Such views were paraphrased as follows:

"Due to pressure, and because women are not entitled for certain things, they will turn on to their male siblings or partners to support them. It is therefore apparent to empower women." (Male participant).

"It is, therefore, necessary to develop skills for males and females so that they can both contribute to the economy of their communities." (Female participant).

The above responses indicate that many of the participants recognized the need of women 
empowerment and the effects of imbalances between men and women. These instances do not allow men and women to participate in the economy of their communities. This argument has also been supported by Madambi reporting on the experiences of certain Zimbabwean women who set out to disapprove the "patriarchal stereotype that women are "housewives"” $(2020,12)$. She states that "against all odds", the women (who were migrants to South Africa) became role models in proving that women's "capabilities and aspirations benefited them, their family units and country". They indeed became appreciated by their families and their community for "creating new norms" for acceptable behavior, which "broke the shackles of gender stereotyping" $(2020,12)$.

\section{Control of power}

Regarding the control of power, we can see again that the recognition that women typically suffer discrimination vis $\bar{a}$ vis men and have fewer decision-making powers in various arenas of life was disadvantageous not only for the women. This was illustrated and paraphrased in expressions such as:

"women will not have power to control their wellbeing. Affect their basic needs such as shelter and on important problems that affect them in everyday life." (Female participant).

Another woman supported the view that was expressed, and her views were paraphrased as follows:

"Women must be awarded with equal treatment so that they can effectively compete with men for better jobs." (Female participant).

"The potentials that women have should be acknowledged." (Female participant).

\section{RESPONSES OF THE PARTICIPANTS IN THE SECOND SET OF MIXED FOCUS GROUP DISCUSSIONS IN 2018}

Follow-up Focus Group sessions were centered on the programs offered by Public Community Learning Centres in the Eastern Cape in contributing to the alleviation of gender disparities in the Eastern Cape. What we highlight below in our commentary are again the manifestations of some shifts in attitudes/ideas and transformation of participants' understandings in terms of different gender relationships and more especially on the side of men. In the second set of Focus Group discussions both men and women suggested new ideas for mitigating gender disparities, and both seemed to more readily appreciate that traditional gender stereotypes can be counterproductive for both men and women. Below we translate and paraphrase their suggested 
strategies for reducing gender inequalities.

\section{Gender sensitisation}

The responses of the participants are paraphrased below:

"Gender related studies must be incorporated in the curriculum and gender education should be regarded as a core subject in our centres." (Male participant).

When further asked on whether their Public Community Learning Centres have sensitized them to all the aspects and concerns related to gender education, their views were paraphrased as follows:

"Gender issues are not included in our curriculum." (Female participant).

"Courses that are emphasized touches on issues of human rights but not on issues of gender equality in education." (Female participant).

"We need to be sensitized on issues of masculinity and femininity." (Male participant).

In response to the aspects of human rights topics covered in, for example, a program called, Life Orientation, participants were also asked on whether these topics could alleviate gender inequalities in their communities. Their responses are paraphrased as follows:

"We normally try to challenge these instances, but the problem is that our community members have homogenized these issues of gender inequalities in our communities." (Female participant).

"We sometimes fear to question the norms and beliefs of our culture." (Female participant).

These responses suggest that Public Community Learning Centre programs although covering aspects of democracy and human rights do not, however, integrate gender issues into all the subjects offered at these centres. Consequently, there is a need for gender sensitization on gender issues to be integrated in into the curricula of Public Community Learning Centres so that all adult learners are better equipped to confront the challenges they encounter in their communities when it comes to questions of gender inequality.

\section{Breaking down traditional stereotypes}

The following paraphrased responses indicated the options participants suggested for challenging restrictive cultural beliefs regarding gender roles:

"In churches, sports facilities, weddings, and in schools, community members must critique sociocultural beliefs and find ways of reducing gender disparities." (Male participant).

"Men and women must identify their commonalities, differences, and find ways of living together 
as sisters and brothers." (Male participant).

Here we can see the principle of harmony as endorsed by Chilisa and Ntseane $(2010,618)$ coming the fore as a value to be nurtured. Some women, however, felt that there is still a need for women to empower themselves as part of the process of women speaking as a collective (in solidarity) about their needs/grievances:

"Women must be empowered or speak out on their behalf, but adult centres should support women to be able to voice their grievances." (Female participant).

"Women must work as team in raising their grievances with one voice." (Female participant).

\section{Improving relations between men and women}

Most of the participants in the mixed Focus Group discussions suggested that to alleviate gender inequalities in the Eastern Cape, better relations between men and women should be improved. The following paraphrased response emphasized:

"If men can see women as their sisters, the gender inequalities can be improved." (Male participant).

All in all, the selection of all these responses attempted to outweigh the "normal" weight given to men's voices and so, at least this was a forum where men were expected to listen to women's voices, with the encouragement of the researcher and, in this context these (new) ideas were seen to emerge.

\section{DISCUSSION}

In the course of identifying the themes and the kinds of responses made in relation to the themes by both men and women participants, it was evident how changes were being made by the participants to their thinking about gender issues and in their considering how they may be better able to relate to each other in terms of less stereotypical gendered relationships. This changing dynamic could well be seen to be consistent with a theoretical lens stemming from African feminism, which does not see a struggle between men and women as much as looking forward to a "better" existence for all that is, for the collective wellbeing in the family and community. In discussing African forms of feminism, Amaefula avers that there is no point in insisting that "sexism hardly existed in most traditional African societies" (prior to colonisation) and that Africans "neither equated men with superiority and women with inferiority" (2021, 294). Amaefula further states that it is more correct to suggest that "the extent of devaluation of women varied from one society to another" $(2021,294)$. He suggests 
that in looking forward, what is important is not to "project men as a primary enemy of women" because this will cause "African feminisms to remain remote to many African men" (2021, 299).

Amaefula states that overall, we (as a collective concerned with gender questions) cannot deny men's complicity in "instituting masculine hegemony" $(2021,299)$; but he suggests that the implications of the feminist movement, including African feminism, for black women are complex. In this article we have tried to show how the male and female participants in the mixed Focus Group discussions were able to develop some rapprochement of perspectives and we suggest that such mixed Focus Group discussions can indeed become a forum for this kind of conversation in other contexts too. We believe we have offered enough detail on our approach to the problem of gender inequality so as to encourage the taking up and applicability of eFocus Group discussions as way of collecting data and interpreting research findings in other research contexts too.

\section{RECOMMENDATIONS}

Premised on our research work, findings comprise specific actions that were proposed by the participants that can empower Public Community Learning Centres to reduce gender inequalities in the Eastern Cape. These include encouraging gender equality, breaking down traditional gender stereotypes and promoting social justice in Public Community Learning Centres in the Eastern Cape (see, Tawana 2019, 163-170)

In summary, the following recommendations based in the research findings are made to alleviate gender inequalities in Public Community Learning Centres in the Eastern Cape:

\section{Improving relations between men and women}

Improved relations between women and men cannot be achieved by women alone, men must be integrated in the process. In other words, ways must be found of encouraging men to understand gender equality and its positive effects on the commnity. Men should also start to see women as their sisters in changing their attitudes towards woman in the community.

\section{Breaking down traditional stereotypes}

Traditional gender stereotypes should be challenged and revised in attempts at reducing gender inequalities in communities in the Eastern Cape.

\section{Gender sensitization}

Gender sensitization should form part of the curriculum in Public Community Learning Centres 
because education that is gender sensitive benefits both men and women.

\section{Redress}

Regarding redress, adult facilitators in Public Community Learning Centres should be gender sensitized and engage in dialogue with female adult learners so that female adult learners can voice their opinions on matters being discussed in Community Learning Centres without fear of discrimination (see, Tawana 2019, 163-164)

\section{CONCLUSION}

In closing, these recommendations address the problem under investigation, namely, Public Community Learning Centres in the Eastern Cape in their present form are not successful in promoting equity and redress. As a result, they do not contribute to mitigating gender disparities in Public Community Learning Centres in the Eastern Cape. By taking note of and embracing these recommendations made above, the Department of Higher Education and Training should 1 be able to ensure that Public Community Learning Centres promote gender equality and in doing so, contribute in alleviating gender inequalities in Public Community Learning Centres in the Eastern Cape.

\section{REFERENCES}

Amaefula, R. C. 2021. "African feminisms: Paradigms, problems and prospects." Feminismo/s 37: 289305.

Anney, V. N. 2014. "Ensuring the quality of findings of qualitative research: Looking at trustworthiness criteria." Journal of Emerging Trends in Educational Research and Policy Studies 5(2): 272-281.

Adyanga, F. A. 2019. "Ancient governance in Africa." In Gender, democracy and institutional development in Africa, ed. N. Wane, 37-65. London: Palgrave McMillan.

Bantu, B. A. 2013. "Claiming Self: The role of Afrikology in social transformation." Scriptura 12(1): $1-12$.

Buswell, C. and Y. Corcoran-Nantes. 2018. "Precarious liaisons: Gender, moral authority and marriage in colonial Kenya." In Balancing individualism and collectivism, ed. J. J. McIntyre-Mills, N. R. A. Romm, and Y. Corcoran-Nantes, 295-414. Cham: Springer.

Chilisa, B. 2009. "Indigenous African-centered ethics: Contesting and complementing dominant models." In The handbook of social research ethics, ed. D. M. Mertens and P. E. Ginsberg, 407426. London: Sage.

Chilisa, B. 2012. Indigenous research methodologies. London: Sage Publications.

Chilisa, B., T. E. Major, and K. Khudu-Petersen. 2017. "Community engagement with a postcolonial, African-based relational paradigm.” Qualitative Research 17(3): 326-339.

Chilisa, B., and G. Ntseane. 2010 "Resisting dominant discourses: Implications of indigenous African feminist theory and methods for gender and education research." Gender and Education 22(6): $617-632$.

Creswell, J. W. 2003. Research design: Qualitative, quantitative, and mixed methods approaches. $2^{\text {nd }}$ Edition. Thousand Oaks: Sage. 
Creswell, J. W. 2013. Quantitative inquiry and research designs: Choosing among five approaches. $4^{\text {th }}$ Edition. London: Sage Publications.

Creswell, J. W. and G. N. Poth. 2018. Qualitative inquiry and Research Design Choosing Among Five Approaches. $4^{\text {th }}$ Edition. London: Sage publications.

Klassen, S. and F. Lamanna. 2009. "The impact of gender inequality in education and employment on economic growth: New evidence for a panel of countries." Feminist Economics 15(3): 91-132

Kovach, M. 2009. Indigenous methodologies: Characteristics, conversations and contexts. Toronto: University of Toronto Press.

Lincoln, Y. and E. G. Guba. 1985. Naturalistic inquiry. London: Sage.

Lindsey, L. L. 2005. Gender roles: A sociological perspective. London: Prentice Hall.

Madambi, S. 2020. "Breaking the shackles of gender stereotyping to create new norms: The case of Zimbabwean migrant women in Mthatha Town." Gender Questions 8(1): 1-15.

Matshidze, P. E. 2013. "The role of Makhadzi in traditional leadership among the Venda." $\mathrm{PhD}$ thesis in the Faculty of Anthropology and Development studies, University of Zululand.

Mazile, B. M. 1998. "The portrayal of women in social studies and history textbooks used in Botswana's social studies and History Textbooks." Unpublished PHD Thesis. Western Kentucky University.

Ngulube, Z. 2018. "The influence of Traditional gender roles and Power relations on women and girls' education and health in Northern Ghana." B.A Thesis. University of Iceland School of Education.

Okoji, O. O. and O. O. Ladeji. 2014. "Influence of adult literacy education on socio-economic empowerment of rural women in Oyo State, Nigeria." Gender and Behaviour 12(1): 6016-6026.

Oyewumi, O. 2002. "Conceptualising gender. The Eurocentric foundations of feminist concepts and the challenge of Africa epistemologies." Journal of Culture and African Women's Studies 2(1): 1-9.

Romm, N. R. A. 2015. "Conducting focus groups in terms of an appreciation of indigenous ways of knowing: Some examples from South Africa." Forum Qualitative Sozialforschung/Forum: Qualitative Social Research 16(1): Art. 2

Tawana, X. 2019. "A critical investigation of the role of Community Learning Centres in Mitigating gender disparities in the Cacadu District of the Eastern Cape." Doctor of Education thesis, University of South Africa.

United Nations. 2006. The millennium development goals report. New York: United Nations. 